\title{
Ad hoc review of the IUGS Commission for the Management and Application of Geoscience Information (CGI)
}

Date and venue of the review:

24-25 September 2009 German Geological Survey (BGR) Building, Hannover, Germany.

\author{
Ad hoc Review Committee members: \\ Peter Bobrowsky - IUGS Secretary- \\ General (ARC Chair) \\ Colin Simpson - IUGS Councillor \\ (ARC Secretary) \\ Jonas Satkunas - Deputy Director - \\ Lithuanian Geological Survey \\ Brian Marker (Independent Consultant)
}

\section{CGI Council Member Participants \\ Kristine Asch (CGI Chairperson) - Germany \\ Ian Jackson (CGI Secretary General) - United Kingdom}

\section{Rationale for the Review}

The IUGS Commission COGEOINFO the forerunner of the current Commission for the Management and Application of Geoscience Information (CGI) was initially established by the IUGS Executive Committee (EC) in the 1990s. It was formally reactivated into the new CGI Commission by the IUGS EC at the 2004 IGC in Florence. A new CGI Council for the timeframe 20082012 was elected and endorsed by the IUGSEC at the 2008 IGC in Oslo. Since reviews of Commissions are normally undertaken on a 4-year basis the IUGS EC during the Annual Meeting in January 2009 agreed that the CGI should be reviewed and a Review Committee was established to comprise two EC Members: P. Bobrowsky and C. Simpson, plus a maximum of three external individuals. The CGI was duly notified of the forthcoming review and provided with all relevant documentation regarding the Review process, ARC guidelines, etc.

The CGI provided the Review Team with all necessary background information regarding their past activities including copies of their own Terms of Reference, annual reports for the period 2004-2008, their 4-year report (2004-2007), and referred the Team to their quite informative website at http:// www.cgi-iugs.org/

\section{Information to be considered}

At the commencement of the Review process in Hannover the ARC Chair Peter Bobrowsky outlined the background for the review, the requirements for routine IUGS reviews of Commissions, the types of issues to be addressed, and the overall process to be followed. He outlined the Terms of Reference (TOR) of IUGS Ad-Hoc Review Committees (also previously sent to the CGI), and presented Copies of the "Report of IUGS Commission 8 on IUGS Rules for Commissions, Task Groups, and Projects" to all in attendance.

\section{Summary of the interviews with CGI Review participants}

The Review addressed a range of items but in particular focussed on the following items:

- progress relative to the original planned activities over the past 4 years;

- successful items, events, products and activities in the Commission;

- main problems encountered by the Commission;

- financial situation of the Commission;

- CGI Working groups and their progress;

- relationships with the IUGS and other international bodies; and

- their proposed Action Plan for 20082012.

In many cases the CGI participants supported their answers using digital presentations, including relevant items from their website as well as paper product examples of their past activities.

The current main CGI projects and technical collaboration activities involve:

1. Interoperability Working Group has developed XML based standards (GeoSciML) to enable seamless web integration of data hosted by different agencies, and also the data transfer for OneGeology and the EU INSPIRE framework.

2. Multi-lingual Thesaurus Working Group (MTG) is developing a core multilingual vocabulary for the geosciences which will be easily accessible (including on the web), and available free of charge, and the standard basis for the GeoSciML geology exchange language.

3. Metadata forum - the rapid growth of the internet has raised the importance of Metadata.
The work of CGI was also a major stimulus for the OneGeology concept and CGI councillors and members are playing the key roles in the running of this project which is carried out with the full support of IUGS. OneGeology is improving the accessibility of geological map data using interoperable web based systems. It is a collaborative project of the geological surveys of the world.

All of the CGI activities listed are proving to be very relevant, timely, and are attracting worldwide interest.

The CGI has initiated a "members" section on their website which allows anyone interested in their activities to become a "member". The membership statistics give an overview of the worldwide growing interest in CGI activities as follows: $2004-104$ members in 37 countries; 2005 - 138 members in 49 countries; 2006 - 161 members in 50 countries; 2007 - 211 members in 57 countries; 2008 - 229 members in 63 countries. By 2008 the CGI website received over 9,500 visitor sessions and 92,800 hits. The OneGeology project has been particularly successful following the launch of the portal at the 2008 IGC in Oslo. By 2008 it had 94 nations participating. Based on OneGeology a related project feeding into OneGeology global has been developed with European Commission funding (One Geology- Europe). Another related project has now been developed by the National Science Foundation in the USA.

The CGI has been very active in outreach with a successful geoscience information symposium at the 2008 IGC in Oslo, and also two significant and successful workshops in Africa (Maputo 2006, Namibia 2009). The African workshops focused on bringing together national experts and relevant authorities to exchange and transfer geoscience knowledge and best practice digital standards etc. It attracted attendees from half the African nations. CGI obtained major financial sponsorship (Euro 125,000) from the German Government for the Namibia Workshop. The CGI representatives have been active in attending and promoting CGI activities, at relevant global symposia and workshops related to geoscience data. The Review Team found minimum problems with the CGI efforts to expand outreach activities over the past 4 years. 


\section{Issues}

Particular difficulties facing the CGI are that their major activities are conducted by a relatively small and dedicated team and they are facing difficulties attracting additional people and outside assistance (a common problem with such groups). They have also had difficulties attracting academics into their working groups to provide technical expertise.

Funding for international activities is a problem given that such activities are expensive and they have been unable to attract many external sponsors. A lack of travel money means that it is difficult to get people in various countries involved in CGI activities. Sending a group to specific countries to give courses on the geoscience information requirements, how to get and use internet freeware, etc., would be a priority if funds were available. The relative low expenditure from the CGI budget over the past 3 years has been due to a serious need to save for investment for their pending international workshops. The unexpected 2008 financial aid from the German government means that they still have their saved budget to assist with their planned international workshops over the next 2 years.

The Multi-lingual Thesaurus Working Group (MTG) performance has been complicated by personal issues within the membership. Progress has been slower than all would wish. However, we now see positive signs as a result of active Linking to the CGI IWG at the recent St. Petersburg workshop,
INSPIRE was implemented in 2007 as a Directive of the European Commission and will drive standardisation and harmonisation efforts for spatial information across the EU. CGI is playing a major role in the implementation of the Directive through their membership of the EC Regulations Drafting Team and the creation of the GeoSciML exchange language. The CGI believes that IUGS backing for INSPIRE is important.

\section{Ad hoc Review Committee Comments}

During the review, the ARC members made comments/suggestions aimed at improving CGI activities. These included:

- putting some of the website pages that are currently only available to registered Members, into the open front page information to make the CGI activities more readily obvious.

- need to promote on the web the advantages of membership. Having CGI Annual Reports readily available on the website would also assist in informing people of CGI activities.

- ICSU grants should be explored as one avenue for obtaining additional funds.

\section{Conclusions and Recommendations}

Since its formal reactivation in 2004 the CGI has made significant advances in developing models and promoting standards for digital geological data which have been accepted and used by a significant number of countries. The process of standard development and promotion is currently ongoing.
Based on this Review the ARC Committee recommends the following:

1. That the IUGS continue support of the CGI activities to 2012.

2. Given the high possibility that all participants in this review will attend the 2012 IGC in Australia this ARC Committee and the CGI representatives to the ARC (CGI Chairperson and CGI Secretary General) should reconvene early at the IGC to review the 2012 status of CGI so that recommendations on the future of the CGI beyond 2012 can be presented to the IUGS EC meeting at the IGC.

3. That the CGI Committee maintain very close links with the recently formed IUGG Commission on Data and Information (UCDI) to ensure that the geophysical sciences are aware of CGI activities and that there is a minimum of duplication of effort.

4. That the CGI Council endeavor to increase the activities of their MTG to try and complete their multilingual vocabulary for the geosciences by the end of 2012 to support the requirements of the European Commission.

5. That the CGI spearhead a multi-union ICSU grant application in late 2010 .

The ARC members acknowledge the exceptional support of the CGI and congratulate them for operating such a successful IUGS Commission.

\section{Peter T. Brobrowsky}

IUGS Secretary Genreal

Email:pbobrows@nrcan.gc.ca 